\title{
The Development of Organizational Commitment Scale for Non-profit Organization
}

\author{
Afifah At Thohiroh*, Mayadha Kristalindari, Afiyana Eka Nurilla, Lukita Mardhiah, Septiani Khaerunnisa, \\ Dewi Maulina \& Nurul Arbiyah
}

Faculty of Psychology, Universitas Indonesia, Depok, 16424, Indonesia

*E-mail: thohiroh.afifah@gmail.com

\begin{abstract}
The increasing number of non-profit organizations followed by the needs of having committed members and also the weaknesses in the existing instruments of organizational commitment encourages the development of a Non-Profit Organizational Commitment Scale (NPOCS). NPOCS was developed based on Three-Component Model, a model implying that commitment towards an organization consists of three components; affective, normative, and continuance aimed to describe organizational commitment in the non-profit context. Participants are 74 members of non-profit organizations in Greater Jakarta area. NPOCS consist of 45 items by using a 4-point Likert scale. The reliability testing using Cronbach's alpha showed that NPOCS has high internal consistency, either total $(\alpha=.89)$ or each component ( $\alpha$ affective commitment $=.82 ; \alpha$ normative commitment $=.78$; and $\alpha$ continuance commitment $=.76$ ). The validity testing using concurrent validity with turnover intention as its criterion suggested that NPOCS is valid in describing current trend of turnover intention in members of the non-profit organization, either total or each component $(\mathrm{p}<0.05)$. The result from item discrimination analysis indicates that most items in NPOCS could distinguish individuals who have high and low organizational commitment. From all the psychometric analysis of NPOCS, 30 best items were selected.
\end{abstract}

Keywords: non-profit organization; organizational commitment; turnover intention.

\section{Introduction}

The non-profit sector is one of the fastest growing categories of organizations around the world (Lewis, 2005). To date, there is no definitive data on the number of non-profit organizations in the world. However, in the United States, the number of nonprofits currently stands at two million organizations (Nonprofit HR, 2015), which increased by $45 \%$ from 1.1 million in 2009, according to The New York Times. This growth is predicted to keep increasing each year to accommodate various volunteer needs in various sectors, such as education, health, sport, art and cultural, religion, politic, and others (Nonprofit HR, 2015). In Indonesia, there are also quite a number of nonprofit organizations. Based on data obtained from the Ministry of Law and Human Rights in 2009, 21,699 non-profit organizations are legally registered and an estimated 21,301 other non-profit organizations that have been established but have not registered themselves (Suyanto, 2010). Compared to profit-based and non-government organizations, a non-profit organization has three unique characteristics: 1) noncoercive participation and mainly relied on volunteers, 2) managed to run the company without distributing profits to the stakeholders, 3) existed without clear lines of ownership or accountability (Frumkin, 2002).

The rapid development of the non-profit organization raises a new need for human resources because an organization essentially is composed of three elements, namely goals, people, and plans (Seniati, 2002). Not only does it require large amounts of human resources, but non-profit organizations also need highly committed human resources. Committed human resources are important since the sustainability of non-profit organizations is highly dependent on the dedication and support of stakeholders, such as paid-workers, board members, volunteers and donors (HaskiLeventhal \& Bargal, 2008; Tsay \& Turpen, 2011). The existence of highly committed human resources in the organization is one of the predictors of job satisfaction, work motivation, and positive work 
performance (Mathieu \& Zajac, 1990) which positively impact on organizational effectiveness and productivity (Kwon, Bae, \& Lawler, 2010). Conversely, low-committed human resources in the organization is a predictor of absenteeism, truant behavior, turnover and turnover intention (Meyer \& Allen, 1997). All of these can pose a risk of disrupting the overall effectiveness of non-profit organizations (Armstrong, Bluitt-Fisher, LopezNewman, Paul, \& Paul, 2009). Therefore, it's necessary to know and understand the commitment of the non-profit organization's members so that we can identify members who tend to generate negative work behaviors. To achieve this, we need a measurement that is capable of measuring the organizational commitment of non-profit organization members.

Organizational commitment refers to the psychological state that binds relationships between individuals and organizations and has an impact on individuals, such as whether or not individuals stay in the organization (Allen \& Meyer, 1990). One concept that is widely used to understand organizational commitment is the Three-Component Model or TCM proposed by Allen and Meyer (1990). TCM is a multidimensional concept that explains that organizational commitment consists of three components, namely affective, normative, and continuance commitment. Affective commitment refers to the employee's emotional attachment to, identification with, and involvement in the organization; normative commitment reflects a feeling of obligation to continue employment; continuance commitment refers to an awareness of the costs associated with leaving the organization (Meyer \& Allen, 1991).

In the non-profit context, some researchers have studied existing organizational commitment measurements with reference to the TCM concept. Some of the studies show reliable test results (e.g. Vuuren, de Jong, \& Seydel, 2008; Valeau, Mignonac, Vandenberghe, \& Turnau, 2013) and some do not (e.g. Bright, 2001, Preston \& Brown, 2004; Dawley, Stephens, \& Stephens, 2005; McMurray, Pirola-Merlo, Sarros, \& Islam, 2010). Thus, it can be said that the reliability test results against the existing instruments are not consistent. When these organizational commitment measurements are used in the context of profit organizations, reliability tests show more consistent results (e.g., Guttierez, Candela, \& Carver, 2012; Curtis \& Day, 2013; Mohammed \& Eleswed, 2013).
Based on that, it can be assumed that the use of the TCM concept is likely to depend on the context of the application. This assumption is supported by Boezeman dan Ellemers (2007) who stated that TCM might be used differently in the context of profit and non-profit organizations.

Beside inconsistent reliability values, another weakness found is that previous studies did not involve all members of the non-profit organization but limited only to members with specific positions within the organization. For example, in the studies conducted by Dawley, Stephens, and Stephens, (2005), Boezeman and Ellemers (2007), Moston (2007), and Valeau et al., (2013) the participants were only volunteers in non-profit organizations, while in the study conducted by Vuuren, de Jong, and Seydel (2008), the participants were paid and unpaid worker from non-profit organizations. Therefore, it can be said that there is no reliable organizational commitment measurement yet for all members of the non-profit organization. An organizational commitment measurement that can accommodate all members of the non-profit organization is possible to construct because volunteers, paid-workers, unpaid-workers and board members have similar characteristics, under the auspices of non-profit organizations, regardless of the difference in status and compensation earned by them.

In addition, some experts believe that not all components of TCM apply to different organizational contexts, especially non-profits (Boezeman \& Ellemers, 2007; Moston, 2007). Studies conducted by non-profit organizations show that unlike affective and normative components, the relevance of the continuance component to the commitment of members of non-profit organizations is still debated in various literatures (Liao-Troth, 2001; Stephens, Dawley, \& Stephens, 2004; Dawley, Stephens, \& Stephens, 2005; Boezeman \& Ellemers, 2007; McMurray, Pirola-Merlo, Sarros, \& Islam, 2010; Valeau, Mignonac, Vandenberghe, \& Turnau, 2013). This is due to the basic nature of continuance which refers to the consideration of profit and loss, whereas most human resources in non-profit organizations work with the primary objective of being able to meet their personal needs, such as self-need for charity and not solely material fulfillment (Hartenian \& Lilly, 2009). Therefore, the continuance component is considered irrelevant to the context of members' commitment to the nonprofit organization so that some studies do not 
include it in measuring commitment in non-profit organizational (e.g., Boezeman \& Ellemers, 2007; Moston, 2007).

If further examined, the issue underlying the lack of continuance component relevance for non-profit organizational contexts is the limitation of compensation regarding profit and loss considerations. Nonetheless, members involved in non-profit organizations can consider profit and loss from other aspects, such as power, time, status, prestige, or relationships (Shkuro, 2011). This kind of consideration has not been captured by the existing organizational commitment measurements. Therefore, we consider the TCM concept remains applicable to non-profit organizational contexts and may continue to include continuance as a component of measurement.

Based on the above explanation, it can be concluded that a specific organizational commitment measurement for volunteers in non-profit organizations is important to develop. This is due to 1) the dedication and support from non-profit members of the organization is crucial as an organizational resource, 2 ) the positive and negative impacts of members who have high and low commitment to the organization, 3) TCM reliability test results that are inconsistent in the context of non-profit organizations, 4) TCM concepts that depend on the context of use, 5) unavailability of reliable organizational commitment measurement capable of accommodating all members of the nonprofit organization, and 6) consideration of profit and loss of members of non-profit organizations on continuance components not yet captured by existing measurements. Therefore, this study aims to develop an instrument capable of measuring the organizational commitment of members of nonprofit organizations. This instrument is called NonProfit Organizational Commitment Scale (NPOCS). Before using the instrument, it is necessary to conduct psychometric testing to ascertain that the instrument meets the requirements of a good measurement. Thus, the research question to be answered in this study is whether the NPOCS is reliable in the sense of consistently measuring one construct, valid to measure organizational commitment, and having items that can distinguish whether a member has high or low organizational commitment for the further purpose (e.g. appraisal or determining intervention baseline).

\section{Methods}

Sample. 74 participants were involved in the study. The participants are members of non-profit organizations from various sectors, such as education, arts and culture, health, social, religion, and politics in Jakarta, Bogor, Depok, Tangerang, and Bekasi. Participants were asked to fill the scale either offline or online. There were 32 male and 42 female in the study. Mean age of participants was $23.64(\mathrm{SD}=4.65)$. The duration of membership was varied $(\mathrm{M}=26.45$ months, $\mathrm{SD}=34.15$ months $)$.

Measurement. There are three dimensions in the non-profit organizational commitment scale: affective, normative, and continuance. Affective dimension measures how willing a person to stay in the organization as a result of working experience which gives them a sense of comfort and success. Normative dimension measures a person's feeling of obligation to stay in the organization due to internalization of loyalty norm. Continuance dimension measures the need to stay in the organization which is associated with perceived costs. Each dimension is represented by a different number of indicators.

There are five indicators which describe affective dimension: desire to maintain the membership in the organization, perceived positive feelings for an organization, perceived improvement in selfcompetence after becoming a member of the organization, sense of identification in an organization, and emotional attachment to an organization. Next, there are three indicators for normative dimension: the obligated feeling to remain in the organization, the internalized value of loyalty for the organization, and the urge to reciprocate with the organization. Lastly, there are two indicators for continuance dimension: the urge to commit to the organization due to sacrifices that have been made (i.e., time, effort, and money) and limited alternative.

Based on the indicators, 15 items created for each affective commitment (e.g., I feel uncomfortable whenever someone says something negative about this organization), normative (e.g., being a part of this organization is a form of my gratitude towards it), and continuance dimension (e.g., my energy and time spent makes me reluctant to leave this organization). All 45 items produced are developed based on the aforementioned indicators. Organizational commitment in NPOCS was rated by 
a 4-point Likert scale ranging from 'strongly agree' to 'strongly disagree.'

Procedure. The procedure of the development of NPOCS is based on Cohen, Swerdlik, and Sturman (2013), consisting of test conceptualization, test construction, expert judgment, legibility test, try-out test, item analysis, and test revision. Once the construct is selected, the existing organizational commitment measurements, especially in the context of non-profit organizations were tracked, along with its advantages and disadvantages. Based on the literature reviews it's decided that NPOCS would again use the three organizational commitment components, while in the previous measures only two of the components were used (the continuance component is omitted). In this stage, there are ten indicators produced for the three components of organizational commitment that include affective, normative and continuance commitment.

In the test construction stage, we started by selecting the type of the test, where NPOCS is classified as a typical performance test because it measures what individuals typically do in everyday situations. The selected-response items are used for NPOCS items based on the convenience and objectivity in scoring. The objective items used in this test are polytomous items with six alternative responses to each statement. Then, the items are arranged based on the indicators that have been made for each component with the proportion of the target item of 30 with ten items for each component, while the target items for the trial amounted to 45 items with 15 items for each component.

After all the items are done, they went through an evaluation process by experts in psychometric. This judgment process covered the accuracy of the constructs, items, and instructions of the questionnaire. After some revision, the items were judged by a sample group through legibility test to see the quality of the items that have been made, the display of questionnaire, and the instructions. The legibility test was conducted for 12 participants who joined in various non-profit organizations in various sectors (including education, arts and culture, health, social-community, and religious sectors). Based on the feedback obtained, 10 of the 45 items had to be revised and the answer scale was changed from 6 to 4-point Likert. The change was deemed necessary considering some participants expressed difficulty in using the 6-point scale (e.g., hard to choose between "slightly agree" or "agree" and "slightly disagree" or "disagree"). The results of the revisions were then tried out to members of nonprofit organizations in the Greater Jakarta area.

Data Analysis. When processing the tryout results, the reliability of NPOCS is measured by using Cronbach's alpha, that is, to measure internal consistency. Furthermore, its validity is measured by using criterion-related validity in the form of concurrent validity with turnover intention scale as its criterion. Concurrent validity is used because NPOCS aims to look at the current picture of trends in turnover from non-profit organizations so that later some intervention can be done. The turnover intention was chosen as a criterion because it is known as one of the consequences of organizational commitment, where there is a negative correlation between the three components of organizational commitment with turnover trends (Meyer, Stanley, Herscovitch, \& Topolnytsky, 2002). We used turnover intention scale developed by Mobley (1977) and previously adapted by Glorinophika (2014). It consists of three items where each item represents each component of the turnover trend. The item analysis for NPOCS is done using item discrimination, that is, correlating each item with the total score (item-total correlation).

\section{Results}

Based on reliability test using Cronbach's Alpha, the reliability score for the three components and total ranged between .71-.87 (Table 1). This finding of reliability coefficient means that more than $70 \%$ observed score is a variance of true score and the rest come from variance error. Therefore, NPOCS shows a high internal consistency to test one construct, whether it measures each organizational commitment aspects or organizational commitment as a whole.

The validity test of NPOCS using criterion-related validity is done through concurrent validity test, between NPOCS as predictor and turnover intention as a criterion. The result denotes NPOCS as a valid instrument to portray individual tendency to leave an organization. 
Table 1.

The reliability and validity test result on 45 items NPOCS

\begin{tabular}{lccc}
\hline Component & $\boldsymbol{n}$ item & $\boldsymbol{\alpha}$ & $\boldsymbol{r}$ \\
\hline Affective & 15 & .78 & $-.23^{*}$ \\
Normative & 15 & .75 & $-.26^{*}$ \\
Continuance & 15 & .71 & $-.30^{* *}$ \\
Total & 45 & .87 & $-.32^{* *}$ \\
\hline
\end{tabular}

* significant at los .05, one-tailed

**significant at los .01, one-tailed

Based on item discrimination analysis using corrected item-total correlation (Crit), most of the NPOCS items have adequate discrimination or Crit $\geq .2$ (Everitt \& Skrondall, 2010). This finding shows the capability of NPOCS items to differentiate individual with high and low commitment. Item discrimination analysis results are shown in Table 2.

Table 2.

Item discrimination analysis of NPOCS

\begin{tabular}{lcc}
\hline \multirow{2}{*}{ Component } & \multicolumn{2}{c}{$\boldsymbol{n}$ item } \\
\cline { 2 - 3 } & Crit $<.2$ & Crit $\geq .2$ \\
\hline Affective & 2 & 13 \\
Normative & 3 & 12 \\
Continuance & 6 & 10 \\
Total & 10 & 35 \\
\hline
\end{tabular}

The integrative analysis of items to choose 30 items as planned was conducted after reliability and validity test of 45 items. Reliability coefficient for 30 items chosen is between .76-.89. This result indicates NPOCS as a reliable instrument for nonprofit organization commitment. It also shows an increasing score of reliability for each component and as a whole. Validity test for the chosen 30 items also shows an increasing score of correlation between NPOCS with turnover intention. This result suggests that the item analysis based on quantitative and qualitative consideration has been fruitful to eliminate less qualified items. Thus, the 30 final items selected from the integrative analysis are deemed to be better at measuring commitment to a non-profit organization and depicting its member's tendency to leave the organization. These findings are shown in Table 3.

\section{Discussion \& Conclusion}

Discussion. The current study tried to address the limitation of the previous measurement by focus on capturing organizational commitment in non-profit context. Based on the analysis, several major findings were noted. First, in terms of psychometric qualities, NPOCS was proven to be reliable, valid, and able to discriminate individual commitment towards a non-profit organization. NPOCS is capable of measuring the commitment of all members of the non-profit organization, including volunteers, paid-worker, unpaid-worker, and board member which are not addressed in previous existing measurements because they exclusively measure specific members of the organization.

Table 3.

The reliability and validity test result on 30 items NPOCS

\begin{tabular}{lccc}
\hline Component & $\boldsymbol{n}$ item & $\boldsymbol{\alpha}$ & $\boldsymbol{r}$ \\
\hline Affective & 10 & .82 & $-.23^{*}$ \\
Normative & 10 & .78 & $-.30^{* *}$ \\
Continuance & 10 & .76 & $-.37 * *$ \\
Total & 30 & .89 & $-.36 * *$ \\
* significant at los .05, one-tailed & \\
**significant at los .01, one-tailed
\end{tabular}

Second, the current finding was able to address the issue of continuance commitment in previous research. Consistent with our hypotheses, members of the non-profit organization also considered loss and benefit, which have not been captured in the previous measurements. These considerations include effort, status, prestige, and relationship. As Shkuro (2011) points out, these four can be motivations for people involved in non-profit organizations. Based on the above explanation, the continuance dimension in the TCM model proves to be relevant in the context of the non-profit organization.

However, this study has few limitations. Firstly, not all of the questionnaires are administered directly to the respondents, which shows a possibility of important unobserved factors such as the different conditions between participants when filling the questionnaire. Different conditions during the indirect administration of questionnaire completion might include noisy versus conducive situation, whether respondents focused on filling the questionnaire or engaged in other activities while doing it, and whether they answered all the questions independently or with someone else's input. The indirect administration creates difficulty to control the situation of the data collection, so there is a possibility that the different score among participants came from the error of the uncontrolled situation and not from individual differences. The 
other shortcoming of the indirect administration is the minimal observation of the participants. This unobserved condition of participants during data collection may limit the ability to scrutinize any input from the participants during or after completing the scale. Furthermore, the indirect administration also creates difficulty to observe the length of questionnaire completion and response of confused participants. While it is important to see the opinion or response from participants to improve the quality of the questionnaire, it is quite hard to do so considering no direct interactions were made during the administration.

Secondly, the small sample size involved for data collection might affect the small validity coefficient of NPOCS. Small sample size can limit the variability of scores which causes all scores to fall into adjacent range. As a result, the effect of restriction of range might emerge in the form of the small value of coefficient validity (Kaplan \& Saccuzzo, 2005). The restriction of range can be observed in NPOCS total score variance for 45 items that only ranges 107-159 whilst the possible range is $45-180$. Moreover, the total score variance for the 30 final items only ranges 66-114 whereas it is possible to derive score ranging in 30-120. Therefore, albeit proven to be valid in describing the current trend of turnover intention, NPOCS' validity coefficient tends to be not too large. Thirdly, NPOCS validity test only used criterion-related validity and limited to describing the current individual condition. Another validity testing using different method is needed so that NPOCS could be proven more valid and comprehensive. Another limitation of the study is the exclusion of job tenure as a contributing factor in shaping organizational commitment. The study by Allen \& Meyer (1993) revealed that there is a strong correlation between continuance commitment with job tenure. This result indicates that involving participants with short job tenure might be lowering the score of continuance commitment compared to two other dimensions. Future research may address this issue by taking participants' employment tenure into account.

For further research, we strongly recommend using another criterion of criterion-related validity for more comprehensive validity evidence (i.e., job performance and stress level). Applying job performance as criteria might generate an additional benefit of NPOCS in predicting or describing the job performance of the organization members.
Therefore, it is deemed possible to include organizational commitment as one of appraisal aspect for non-profit organization members. Meanwhile, stress level as another criterion might be beneficial for early diagnosis. Referring to survey result by Nonprofit HR (2015), non-profit organization members often having overload works which turn to stress and burnout. This is also reinforced by the research from Meyer, Stanley, Herscovitch, and Topolnytsky (2002) who stated that there is a correlation between organizational commitment and job performance and stress. Further study should also use construct validity test, for example using convergent evidence such as job embeddedness considering these two constructs are related (Van Dyck, 2011) and show a bit of similarity.

Conclusion. Based on the psychometric test results, it can be concluded that NPOCS, both total and per component, have a high internal consistency and validity in describing the current trend of non-profit organization members' turnover. In addition, NPOCS' items, both total and per component, can distinguish between members of non-profit organizations who have high and low organizational commitment. In short, NPOCS is a potential scale that can be used to measure organizational commitment in a non-profit organization.

\section{Reference}

Allen, N. J., \& Meyer, J. P. (1990). The measurement and antecedents of affective, continuance and normative commitment to the organization. Journal of Occupational Psychology, 63(1), 1-18.

Allen, N. J., \& Meyer, J. P. (1993). Organizational commitment: evidence of career stage effects?. Journal of business research, 26(1), 49-61.

Armstrong, L., Bluitt-Fisher, J., Lopez-Newman, L., Paul, D. R., \& Paul, K. R. (2009). Nonprofits in crisis: How to retain employees in the nonprofit sector (UNLV Capstones Report 810). Retrieved from University of Nevada, Las Vegas, Digital Scholarship@UNLV website: http://digitalscholarship.unlv.edu/thesesdissertations/ 810

Boezeman, E. J., \& Ellemers, N. (2007). Volunteering for charity: Pride, respect, and the commitment of volunteers.Journal of Applied Psychology, 92(3), 771-785. doi:10.1037/0021-9010.92.3.771

Bright, J. L. (2001). The commitment of board members of nonprofit organizations (Order No. 3015942). Available from ABI/INFORM Complete; ProQuest Dissertations \& Theses Global. (304686308). Retrieved from http://search.proquest.com/docview/304686308?accountid $=14723$ 
Cohen, R.J., Swerdlik, M.E., \& Sturman, E.D. (2013). Psychological testing and assessment. New York: McGraw-Hill.

Curtis, A., \& Day, A. (2013). The impact of specialist training on professional identity, organisational membership, organisational commitment, and stress in correctional psychologists. Journal of Forensic Practice, 15(2), 130140. doi:10.1108/14636641311322313

Dawley, D. D., Stephens, R. D., \& Stephens, D. B. (2005). Dimensionality of organizational commitment in volunteer workers: Chamber of commerce board members and role fulfillment. Journal of Vocational Behavior, 67, 511-525.

Everitt, B. S., \& Skrondal, A. (2010). The Cambridge dictionary of statistics (4th ed.). New York, NY: Cambridge University Press

Frumkin, P. (2002). On being nonprofit. Cambridge, Mass.: Harvard University Press.

Glorinophika. (2014). Program perencanaan dan pengembangan karir sebagai intervensi untuk menurunkan intensi turnover di PT X (Master's thesis). Universitas Indonesia, Depok.

Hartenian, L., \& Lilly, B. (2009). Egoism and commitment: A multidimensional approach to understanding sustained volunteering. Journal of Managerial Issues, 21(1), 97118.

Haski-Leventhal, D., \& Bargal, D. (2008). The volunteer stages and transitions model: Organizational socialization of volunteers. Human Relations, 61(1), 67-102. doi: $10.1177 / 0018726707085946$

Kaplan, R.M. \& Saccuzzo, D.P. (2005). Psychological testing: Principles, applications, and issues. Belmont, CA: Wadsworth.

Kwon, K., Bae, J., \& Lawler, J. J. (2010). High commitment HR practices and top performers: Impacts on organizational commitment. MIR: Management International Review, 50(1), 57-80. doi:10.1007/s11575009-0023-6.

Lewis, L. (2005). The civil society sector: A review of critical issues and research agenda for organizational communication scholars. Management Communication Quarterly, 19, 238-267.

Liao-Troth, M. A. (2001). Attitude differences between paid workers and volunteers. Nonprofit Management \& Leadership, 11, 423-442.

Mathieu, J.E., \& Zajac, D.M. (1990). A review and metaanalysis of the antecedents, correlates and consequences of organizational commitment. Psychological Bulletin, 108, 171-194.

McMurray, A. J., Pirola-Merlo, A., Sarros, J. C., \& Islam, M. M. (2010). Leadership, climate, psychological capital, commitment, and wellbeing in a non-profit organization. Leadership \& Organization Development Journal, 31(5), 436-457.

Meyer, J. P., \& Allen, N. J. (1991). A three-component conceptualization of organizational commitment. Human Resource Management Review, 1(1), 61-89.
Meyer, J., \& Allen, N. (1997). Commitment in the workplace, theory research, and application. Thousand Oaks, CA: Sage Publications, Inc.

Meyer, J. P., Stanley, D. J., Herscovitch, L., \& Topolnytsky, L. (2002). Affective, continuance, and normative commitment to the organization: A meta-analysis of antecedents, correlates, and consequences. Journal of Vocational Behavior, 61(1), 20-52. doi:10.1006/jvbe.2001.1842.

Mobley, W. H. (1977). Intermediate linkages in the relationship between job satisfaction and employee turnover. Journal of Applied Psychology, 62(2), 237.

Mohammed, F. \& Eleswed M. (2013). Job Satisfaction and Organizational Commitment: A Correlational Study in Bahrain. Journal of Business, Humanities, and Technology, 3(5).

Moston, T. E. (2007). Measuring the commitment of volunteers in community-based sport. In Brown, Raymond, Finger, Glenn, and Rushton, \& (Eds.), Educational Research: who needs it? (pp. 99-110). Queensland, Australia: Griffith University Press.

Nonprofit HR. (2015). 2015 Nonprofit Employment Practices Survey Results. Retrieved from Nonprofit HR website: http://www.nonprofithr.com/wpcontent/uploads/2015/02/2015-Nonprofit-EmploymentPractices-Survey-Results-1.pdf

Preston, J. B., \& Brown, W. A. (2004). Commitment and performance of nonprofit board members. Nonprofit Management and Leadership, 15(2), 221-238.

Seniati, A. N. L. (2002). Pengaruh masa kerja, trait kepribadian, kepuasan kerja, dan iklim psikologis terhadap komitmen dosen pada Universitas Indonesia. MAKARA of Social Sciences and Humanities Series, 10(2).

Shkuro, Y. (2011). Attraction and motivation of millennial generation volunteers by nonprofit organizations (Order No. 1498519). Available from ProQuest Dissertations \& Theses Global. (894263560). Retrieved from http://search.proquest.com/docview/ 894263560? accountid=14723

Stephens, R. D., Dawley, D. D., \& Stephens, D. B. (2004). Commitment on the board: A model of volunteer directors' levels of organizational commitment and selfreported performance. Journal of Managerial Issues, 483504.

Suyanto, D. (2010, June 22). Re: Non-Profit Organization Domestic Review [Web log message]. Retrieved from https://openknowledge.worldbank.org/bitstream/handle/ 10986/12791/704620ESW00Tit0ent0Indonesia0Report.tx $\mathrm{t}$ ?sequence $=2$

Tsay, B.Y., \& Turpen, R.A. (2011). The control environment in not-for-profit organizations: Changing the organizational culture. The CPA Journal, 64-67.

Valéau, P., Vandenberghe, C., Mignonac, K., \& Turnau, A. G. (2013). A study of the relationships between volunteers commitments to organizations and beneficiaries and turnover intentions. Canadian Journal of Behavioural Science/Revue Canadienne Des Sciences Du Comportement, 45(2), 85-95. doi:http://dx.doi.org/10.1037/a0027620 
Van Dyk, J. (2011). The relationship between organisational commitment, retention factors and perceived job embeddedness (Master's thesis). Retrieved from http://uir.unisa.ac.za/
Vuuren, M. V., de Jong, M. D., \& Seydel, E. R. (2008). Commitment with or without a stick of paid work: Comparison of paid and unpaid workers in a nonprofit organization. European Journal of Work and Organizational Psychology, 17(3), 315-326. 